LBL -30.989

DE92 017114

\title{
FORMATION OF BURIED EPITAXIAL Si-Ge ALLOY LAYERS IN Si <100> CRYSTAL BY HIGH DOSE GE ION IMPLANTATION
}

\author{
Kin Man Yu*, Ian G. Brown**, and Seongil Im*** \\ *Center for Advanced Materials \\ Materials Sciences Division \\ and \\ **Accelerator \& Fusion Research Division \\ Lawrence Berkeley Laboratory \\ 1 Cyclotron Road \\ Berkeley, CA $\$ 4720$ \\ *** Materials Science and Mineral Engineering Department \\ University of California at Berkeley \\ Berkeley, CA 94720
}

Presented at the Fall 1991 Meeting of the Materials Research Society

Boston, Dec. 2-6, 1991

This work was supported by the Director, Office of Energy Research, Office of Basic Energy Sciences, Materia's Sciences Division of the U.S. Department of Energy under Contract No. DE-ACO3-76SF00098. 
FORMATION OF BURIED EPITAXIAL Si-Ge ALLOY LAYERS IN

Si $<100>$ CRYSTAL BY HIGH DOSE Ge ION IMPLANTATION

\author{
Kin Man Yu*, Ian G. Brown** and Seongil Im*** \\ *Center for Advanced Materials, Materials Sciences Division and **Accelerator \& Fusion \\ Research Division, Lawrence Berkeley Laboratory, Berkeley, CA 94720 \\ *** Department of Materials Science and Mineral Engineering, \\ University of California, Berkeley, CA 94720.
}

\begin{abstract}
We have synthesized single crystal $\mathrm{Si}_{1-x} \mathrm{Ge}_{\mathrm{x}}$ alloy layers in $\mathrm{Si}<100>$ crystals by high dose Ge ion implantation and solid phase epitaxy. The implantation was performed using the metal vapor vacuum arc (Mevva) ion source. Ge ions at mean energies of 70 and $100 \mathrm{kEV}$ and with doses ranging from $1 \times 10^{16}$ to $7 \times 10^{16}$ ions $/ \mathrm{cm}^{2}$ were implanted into Si $<100>$ crystals at room temperature, resulting in the formation of $\mathrm{Si}_{1-\mathrm{x}} \mathrm{Ge}_{\mathrm{x}}$ alloy layers with peak $\mathrm{Ge}$ concentrations of 4 to 13 atomic \%. Epitaxial regrowth of the amorphous layers was initiated by thermal annealing at temperatures higher than $500^{\circ} \mathrm{C}$. The solid phase epitaxy process, the crystal quality, microstructures, interface morphology and defect structures were characterized by ion channeling and transmission electron microscopy. Compositionally graded single crystal $\mathrm{Si}_{1-\mathrm{x}} \mathrm{Ge}_{\mathrm{x}}$ layers with full width at half maxirnum $\sim 100 \mathrm{~nm}$ were formed under a $\sim 30 \mathrm{rm}$ Si layer after annealing at $600^{\circ} \mathrm{C}$ for $15 \mathrm{~min}$. A high density of defects was found in the layers as well as in the substrate Si just below the original amorphous/crystalline interface. "The concentration of these defects was significantly reduced after annealing at $900^{\circ} \mathrm{C}$. The kinetics of the regrowth process, the crystalline quality of the alloy layers, the annealing characteristics of the defects, and the strains due to the lattice mismatch between the alloy and the substrate are discussed.
\end{abstract}

\title{
INTRODUCTION
}

In recent years, there has been much interest in the alloys of silicon and germanium, $\mathrm{Si}_{1}$. ${ }_{x} \mathrm{Ge}_{\mathrm{x}}$, which have been shown to be promising semiconductor materials for the fabrication of high speed modulation-doped field effect transistors[1] and heterojunction bipolar transistors[2]. In addition to novel device applications, $\mathrm{Si}_{1-\mathrm{x}} \mathrm{Ge}_{\mathrm{x}}$ alloy layers have been used as buffer layers for the growth of Si-Ge strained layer superlattices with novel optical properties. Conventionally defectfree and atomically abrupt $\mathrm{Si}_{1-x} \mathrm{Cie}_{x}$ alloy thin films with $\mathrm{x}$ ranging from $0-50 \%$ can be grown on Si substrates by molecular bearn epitaxy (MBE) [3], limited-reaction-processing (LRP) [4] , and ion beam sputter deposition [5] kechniques provided the layers are below the critical thickness for pseudomorphic growth $[6,7]$. Recently, the growth of $\mathrm{Si}_{1-x} \mathrm{Ge}_{\mathrm{x}}$ alloy layers, in particular buried $\mathrm{Si}_{1-\mathrm{x}} \mathrm{Ge}_{\mathrm{x}}$ layers in $\mathrm{Si}$, using ion beam synthesis (IBS) methods has also been explored [8-11].

In the last few years the ISS technique has been developed and applied to the synthesis of metal silicides in $\mathrm{Si}$. Buried $\mathrm{COSi}_{2}[12-16], \mathrm{NiSi}_{2}[17,18], \mathrm{IrSi}_{3}[19], \mathrm{CrSi}_{2}[13,20], \mathrm{YSi}_{1.7}$ [21], FeSi $[20$ ], etc. have been successfully fabricated by directly implanting energetic metal ions into $\mathrm{Si}$. Using the IBS technique, White et. Al. [13] have synthesized buried epitaxial CoSi $i_{2}$ layers which have electrical properties comparable to those grown by MBE. Despite the initial gaussian distribution of the implanted ions, subsequent annealing of the structure at temperatures $2500^{\circ} \mathrm{C}$ resulted in good layer confinement in the buried silicide structures. The migration of the implanted ions from the tails of the profile towards the center is a result of the existence of a stable silicide phase in the metal-silicon phase diagram. In the case of the Si-Ge system, no such stable phase exists. In fact, Ge atoms are completely miscible in the Si lattice. Therefore when Ge ions are implanted into Si, no significant redistribution of the Ge atoms in the solid state is expected after annealing.

Recently, several investigators have explored the formation of $\mathrm{Si}_{1-\mathrm{x}} \mathrm{Ge}_{\mathrm{x}}$ layers by IBS. Paine et. al. $[8,9,11]$ have studied the IBS of $\mathrm{Si}_{1-x} \mathrm{Ge}_{x}$ using transmission electron microscopy (TEM) and developed a model for the strain relief in compositionally graded SiGe layers. Berti et. al. [10] studied the formation of $\mathrm{Si}_{1-x} \mathrm{Ge}_{x}$ layer by $\mathrm{Ge}$ implantation and laser melting. They found that the Ge atoms redistributed to the surface forming a sharp, epitaxial, defect-free $\mathrm{Si}_{1}$. ${ }_{x} \mathrm{Ge}_{x}$ surface layer after irradiation by a XeCl laser at $1.07 \mathrm{~J} / \mathrm{cm}^{2}$. In our work, we present a study of the formation of buried $\mathrm{Si}_{1-\mathrm{x}} \mathrm{Ge}_{\mathrm{x}}$ epitaxial layers by IBS using a high current metal vapor 
vacuum arc (Merva) ion source. Issues on the solid phase epitaxial regrowth crystalline quality and coherence of the $\mathrm{Si}_{1-\mathrm{x}} \mathrm{Ge}_{\mathrm{x}}$ layers, as well as the recovery of the implanted damage are discussed.

\section{EXPERIMENTAL DETAILS}

(100) oriented Si wafers were implanted with $\mathrm{Ge}$ ions at three different doses, $1 \times 10^{16}$, $1.7 \times 10^{16}$, and $7.0 \times 10^{16} / \mathrm{cm}^{2}$ using the Mevva ion source. The three different doses will be referred to as low, medium and high dose, respectively in this paper. The details of the implantation set-up have been described in previous publications[19,22] and will not be repeated here. The substrate was water-cooled during implantation. The extraction voltage of the low dose implant was $50 \mathrm{kV}$ while that of the medium and high dose implants was $70 \mathrm{kV}$. The mean charge state for the Ge ions produced by the ion source was $-1.4\left(60 \% \mathrm{Ge}^{+}\right.$and $\left.40 \% \mathrm{Ge}^{++}\right)[23]$; since no energy analysis was carried out (broad-beam implantation), the mean implantation energy of the low dose implant was $-70 \mathrm{keV}$ and the mean energy of the medium and high dose implants was $100 \mathrm{keV}$. The $\mathrm{Ge}$ ions were implanted into the Si wafers with $250 \mu \mathrm{s}$ beam pulses at a maximum beam current of $5 \mathrm{~mA} / \mathrm{cm}^{2}$. The bearn pulse repetition rate was limited to 3-5 pulses/second to avoid beam hearing. After implantation, the samples were annealed in the temperature range of $500-900^{\circ} \mathrm{C}$ in a $\mathrm{N}_{2}$ ambient with the surface protected by a bare Si wafer.

The implanted $\mathrm{Ge}$ profiles were measured by Rutherford backscantering spectrometry (RBS) with a $1.95 \mathrm{MeV}$ He ion beam. The RBS experiments were performed at scattering angle $\theta=165^{\circ}$. The solid phase epitaxial regrowth kinetics, the epitaxial quality of the $\mathrm{Si}_{1-x} \mathrm{Ge}_{\mathrm{x}}$ layers and the implantation damage were accessed by ion channeling in the $\langle 100\rangle,\langle 110\rangle,\langle 111\rangle$ axial directions. TEM of cross-sectional specimens was also carried out on some of the samples using the JEOL 200CX TEM at the National Center for Electron Microscopy at the Lawrence Berkeley Laboratory.

\section{RESULTS AND DISCUSSION}

\section{Solid Phase Epitaxy (SPE)}

Figure 1 shows the Ge atomic profiles for the three implants as measured by RBS. The peak Ge concentrations for the three doses correspond to 4 (low), 3.5 (medium), and 12.5 (high) atomic $\%$ while their projected ranges are $35 \mathrm{~nm}, 55 \mathrm{~nm}$ and $60 \mathrm{~nm}$, respectively. Note that the peak $\mathrm{Ge}$ concentration of the low dose sample is slightly higher than that of the medium dose sample. This is due to the higher implant energy of the medium dose implant which results in a wider spread in the Ge distribution and lower peak concentration. The calculated ranges using the

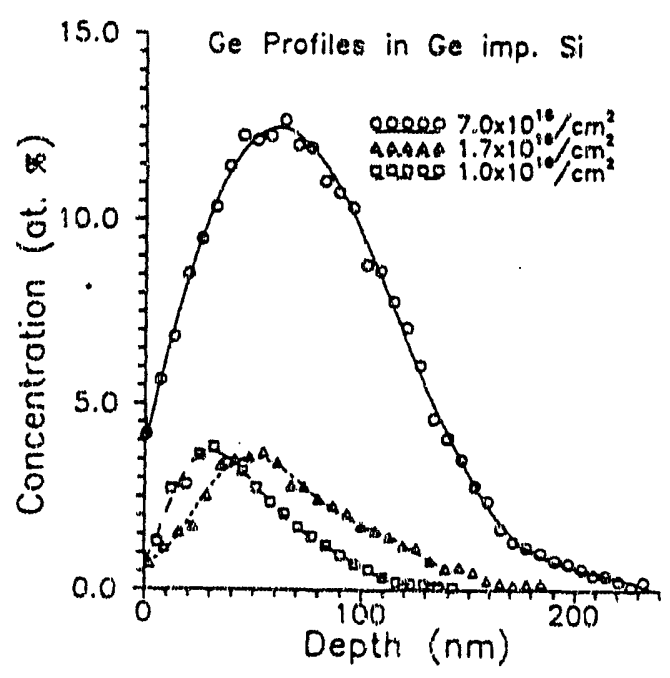

Fig. 1 The Ge atomic profiles in Si for the three different doses measured by RBS.

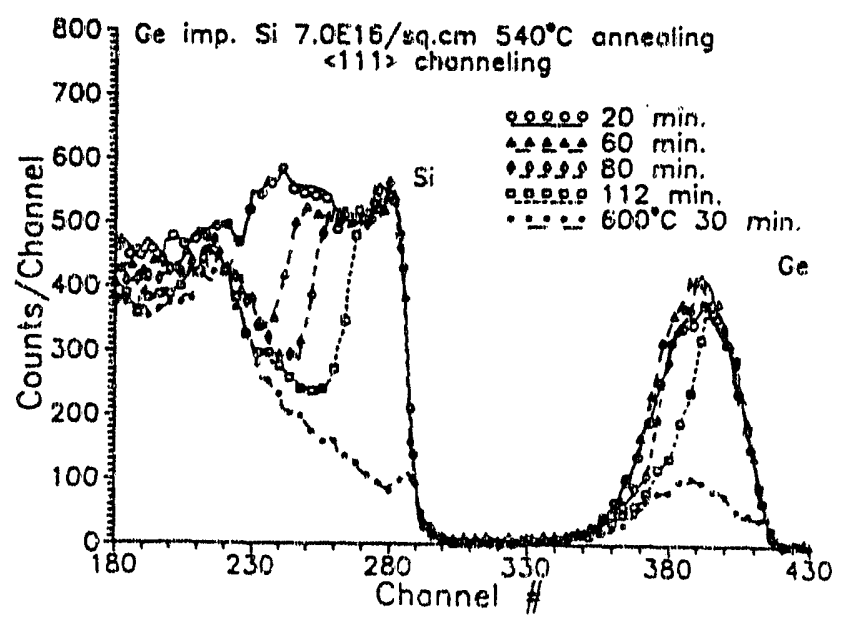

Fig. 2. A series of $<111>$ channeld RBS spectra from the high dose sample annealed at $540^{\circ} \mathrm{C}$ for various time durations. 
LSS theory for '70 keV and $100 \mathrm{keV} \mathrm{Ge}$ ions in a Si crystal are $44 \mathrm{~nm}$ and $59 \mathrm{~nm}$. These

theoretical values agree reasonably well with the experimental values measured by RBS. The broad Ge distributions in Fig. 1 are the results of the multiple charge states of the Ge ions from the Mevva ion source [23]. Ion channeling measurements show that for the as-implanted samples, the amorphous layer thicknessses are $145 \mathrm{~nm}$ for the low dose, $170 \mathrm{~nm}$ for the medium dose, and $210 \mathrm{~nm}$ for the high dose cases.

Solid phase epitaxial (SPE) regrowth kinetics were studied by ion channeling techniques for both the low dose and the high dose samples. SPE is observed at annealing temperatures higher than $500^{\circ} \mathrm{C}$. Fig. 2 shows a series of RBS spectra taken in the $\left.<111\right\rangle$ channeling direction from the high dose sample annealed at $540^{\circ} \mathrm{C}$ for $20,60,80$, and $112 \mathrm{~min}$. The RBS spectrum from a fully regrown sample $\left(600^{\circ} \mathrm{C}\right.$ for $30 \mathrm{~min}$.) is also included for comparison. Note that the regrowth proceeds in a planar fashion with sharp amorphous/crystalline (a/c) interfaces (to within $90 \AA$ ). A cross-sectional TEM micrograph of a partially regrown high dose sample $\left(570^{\circ} \mathrm{C}\right.$ for 25 min.) shown in Fig. 4 (a) confirms the uniform planar a/c interface during SPE. The data in Fig. 2 also shows that the SPE process is a linear function of the annealing time with a regrowth rate of $\approx 1.3 \mathrm{~nm} / \mathrm{min}$. at $540^{\circ} \mathrm{C}$. Arthenius plots of regrowth rate versus annealing temperature reveal that the activation energy for the SPE process, $\triangle E=2.5 \pm 0.2 \mathrm{eV}$ for the low dose sample and $\Delta \mathrm{E}$ $=3.0 \pm 0.2 \mathrm{eV}$ for the high dose case. The activation energy for the low dose sample is very similar to that of SPE Si ( $\triangle \mathrm{E}=2.6 \mathrm{eV})$ [24] while the activation energy for the high dose case is significantly higher. This result is in good agreement with the SPE results of Paine et.al.[25] who found that for $\mathrm{Si}_{1-\mathrm{x}} \mathrm{Ge}_{\mathrm{x}}$ layers grown by UHV-CVD process and amorphized by $\mathrm{Si}$ implantation, the SPE regrowth rate is lower in the Si-Ge alloy layer than in pure Si with an activation energy $=3.2 \pm 0.2 \mathrm{eV}$. However, in our experiment the change in the epitaxial regrowth rate, as the crystallization front approaches regions with higher $\mathrm{Ge}$ concentration is not detectable due to the fact that the original amorphous layer is compositionally graded and the limited resolution of the RBS technique.

\section{Crystalline Quality of the $\mathrm{Si}_{1 \ldots x} \mathrm{Ge}_{\alpha}$ layer}

The quality of the $\mathrm{Si}_{1-\mathrm{x}} \mathrm{Ge}_{\mathrm{x}}$ layers after $\mathrm{SPE}$ is measured by ion channeling along the $<110>$ and $<111>$ axes of the Si substrate. Fig. 3 shows the Ge signals from the random and $<110>$ aligned RBS spectra of the (a) low and (b) high dose samples annealed at various conditions after SPE. A minimum yield for the Ge signal $\chi_{\min }(\mathrm{Ge})=4 \%$ is achieved for the low dose sample just after SPE $\left(600^{\circ} \mathrm{C}\right.$ for $\left.10 \mathrm{~min}\right)$. This is comparable to an unimplanted single crystal $S i\left(\chi_{\min }=3 \%\right)$. The low $\chi_{\min }(\mathrm{Ge})$ in this sample indicates that the $S i_{1 \times X} G e_{X}$ layer is a high quality single crystal. Cross sectional TEM on this sample reveals that the layer is indeed defect-free. Higher temperature annealing at $800^{\circ} \mathrm{C}$ results in an increase in the channeled $\mathrm{Ge}$ (as well as the Si yield in the SiGe layer). We believe that this is due to the relaxation of the strained layer through the production of dislocations in the regrown layer at high temperature.

For the high dose sample, after complete SPE $\left(600^{\circ} \mathrm{C}\right.$ for $30 \mathrm{~min}$.) $\chi_{\min }$ (Ge) is $19 \%$ (Fig.

$3(b))$. The high $\chi_{\min }(\mathrm{Ge})$ means that the regrown layer is a single crystal with high defect

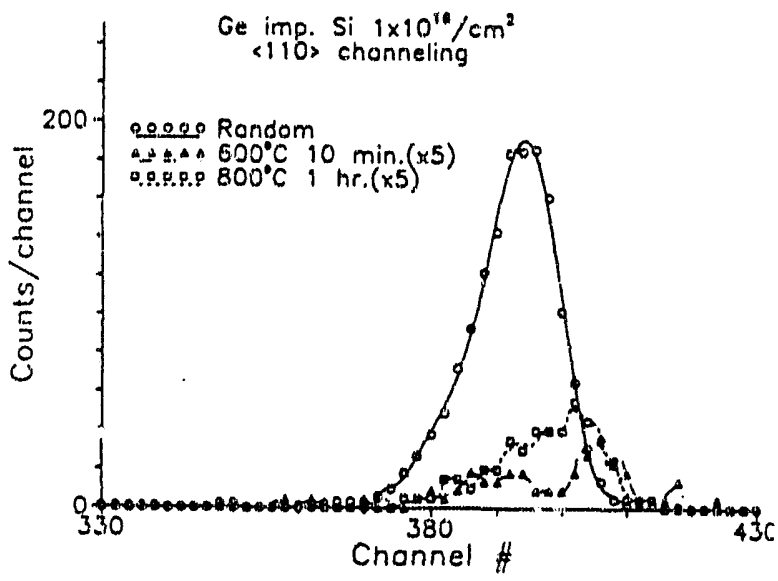

(a)

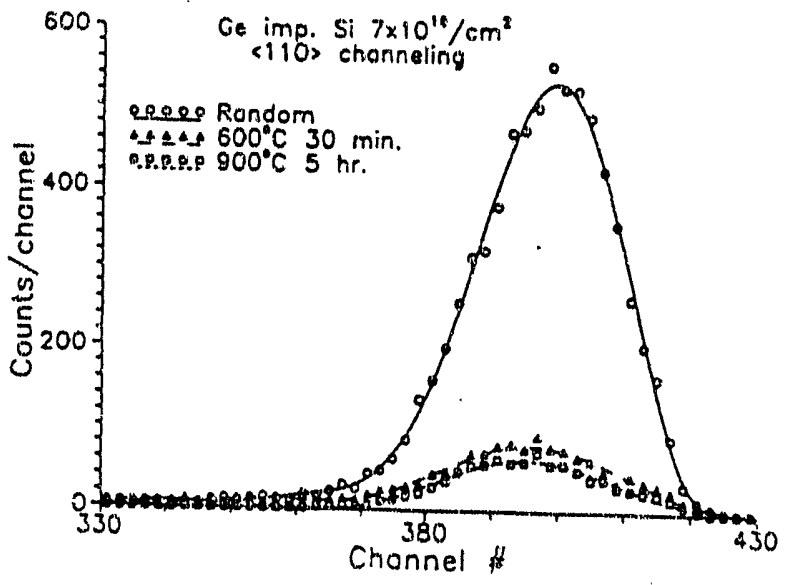

(b)

Fig. 3 The Ge signals from the random and $<110>$ aligned RBS spectra of the (a) low dose, and (b) high dose samples annealed at various conditions. 


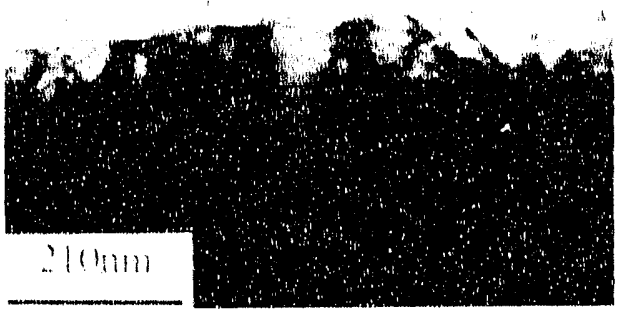

(a)

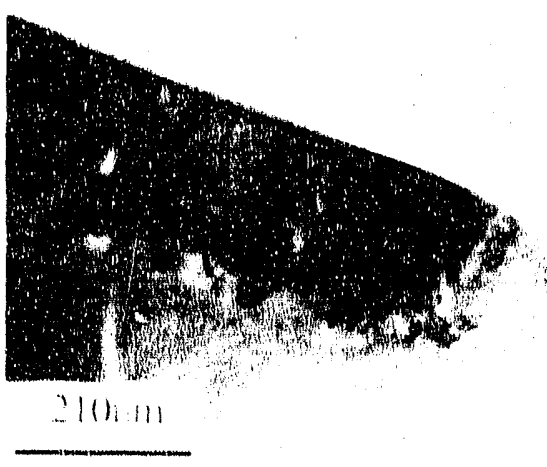

(b)

XBB 910.9213

Fig. 4 Cross-sectional TEM micrographs of the high dose sample annealed at (a) $570^{\circ} \mathrm{C}$ for 25 min. and (b) $900^{\circ} \mathrm{C}$ for $1 \mathrm{hr}$.

density. Further annealing at $900^{\circ} \mathrm{C}$ for $5 \mathrm{hr}$. reduces the $\chi_{\min }(\mathrm{Ge})$ to $15 \%$ indicating that there is an improvement in the crystallinity of the layer. Fig. 4 shows cross-sectional TEM micrographs of the high dose samples annealed at $570^{\circ} \mathrm{C}$ for $25 \mathrm{~min}$. (a) and $900^{\circ} \mathrm{C}$ for $1 \mathrm{hr}$. (b). The sample annealed at $570^{\circ} \mathrm{C}$ is only partially regrown with the $a / c$ interface near the peak of the Ge distribution. Fig. 4 clearly shows that the density of extended defects, namely threading dislocations and stacking faults in the regrown layer is reduced as the annealing lemperature increases. Extended defects are still present in the $\mathrm{Si}_{1-\mathrm{x}} \mathrm{Ge}_{\mathrm{x}}$ layer even after annealing at $900^{\circ} \mathrm{C}$. These extended defects may be the result of high implant temperature (room temperature) [26] or strains due to the high Ge content in the layer. The randorn RBS spectra from the samples annealed at various temperatures show that the redistribution of Ge atoms in the layer even after $900^{\circ} \mathrm{C}$ annealing is not detectable.

The strains due to the lattice mismatch between the $\mathrm{Si}_{1-\mathrm{x}} \mathrm{Ge}_{\mathrm{X}}$ layer and the substrate $\mathrm{Si}$ are accessed by ion channeling in the $<112>$ axis along a $\{110\}$ planar direction. This orientation is chosen so as to minimize the channel stecring effect $[27,28]$. The angular scans of the bulk $\mathrm{Si}$ and $\mathrm{Ge}$ signals for the fully regrown low dose sample $\left(600^{\circ} \mathrm{C}\right.$ for $10 \mathrm{~min}$.) are plotted in Fig. 5. Since the layer is compositionally graded, a definite "kink" angle for ion channeling as is observed in sharp strained layers is not expected. Instead if the system is indeed strained an asymmetric broadened Ge scan should be observed. In Fig. 5 a best fit of the scans does not show any definite kink angle between the Si and Ge scans. However the broadened asymmetric Ge scan indicates that the layer is strained. Angular scans for similar samples after annealing at $800^{\circ} \mathrm{C}$ show only Ge scans similar to those of the bulk Si indicating that the layer after SPE is strained but becomes relaxed after high temperature annealing. Angular scans of the high dose sample after SPE as well as after high

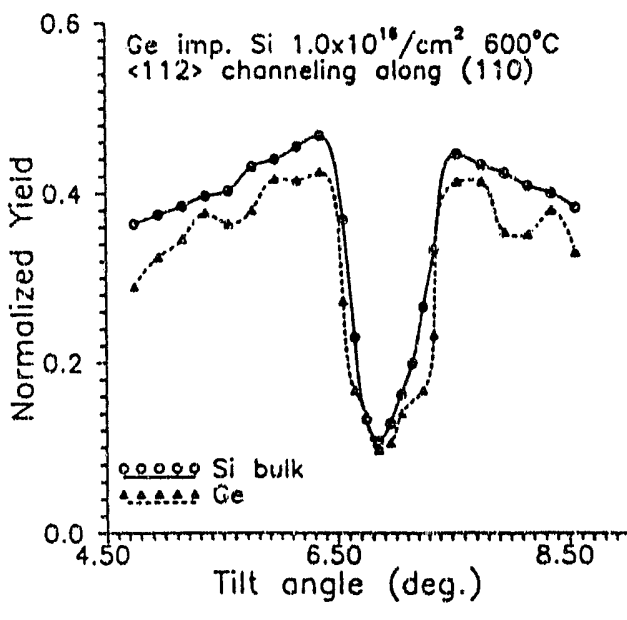

Fig. 5 Angular scans of the Ge from the $\mathrm{Si}_{1-\mathrm{x}} \mathrm{Ge}_{\mathrm{x}}$ layer and the bulk $\mathrm{Si}$ signals across the $\langle 112>$ axis parallel to a $\{110\}$ plane for a low dose sample annealed at $600^{\circ} \mathrm{C}$ for $10 \mathrm{~min}$. temperature annealing show no broadening in the Ge scans. From these channeling data we can conclude that graded $\mathrm{Si}_{1 \times \mathrm{x}} \mathrm{Ge}_{\mathrm{X}}$ layers with peak $\mathrm{Ge}$ concentration around 4 atoric $\%$ are strained after SPE, but these strained layers become relaxed after annealing at temperatures higher than $800^{\circ} \mathrm{C}$. This is also comfirmed by the results shown in Fig. 3(a) which shows the presence of a higher defect density in the $\mathrm{Si}_{1-\mathrm{x}} \mathrm{Ge}_{\mathrm{x}}$ layer annealed at $800^{\circ} \mathrm{C}$ due to strain realxation. Regrown samples with Ge peak concentration at $\sim 13$ atomic \%, however, are not strained. Robinson et. al.[29] studied the coherence of $\mathrm{MBE}$ grown $\mathrm{Si}_{1-\mathrm{x}} \mathrm{Ge}_{\mathrm{x}}$ layers amorphized by implantation and then subjected to $S P E$ at $600^{\circ} \mathrm{C}$. They found that after SPE, layers with $x<18 \%$ remain strained and the quality of layers with $x>18 \%$ deteriorates as a function of $x$. Holländer et. al. [30] found 
quality of layers with $x>18 \%$ deteriorates as a function of $x$. Holländer et. al. [30] found that

annealing of $S i_{1-x} G_{x}$ layers with $x=20 \%$ to above $800^{\circ} \mathrm{C}$ results in relaxation of the layers.

Since our samples were implanted at room temperature to much higher ion doses (1-2 orders of magnitude) than those investigated by Robinson et.al, more implantation induced defects due to defect coalescence during implantation are present. These defects may provide a means for the production of misfit dislocations in the layers. Therefore the critical Ge content for strained layers in our IBS samples is lower than those grown by MBE.

\section{Implantation Induced Defects}

Fig. 6 shows the Si signals of a series of RBS spectra taken in the $<111\rangle$ direction from an unimplanted $\mathrm{Si}$ wafer and the medium dose sample annealed at $600^{\circ} \mathrm{C} 10 \mathrm{~min} ., 800^{\circ} \mathrm{C} 10 \mathrm{~min}$. and $900^{\circ} \mathrm{C} 1 \mathrm{hr}$. The peaks at around channel $\# 240$ correspond to the direct scattering of the beam from the end-of-range (E-O-R) defects just below the original amorphous/crystalline (a/c) interface. It was suggested that these E-O-R defects arise from the Si self interstititals due to recoils during the implantation process. These interstitials then condense into extra planes of atoms forming dislocation loops upon annealing $[31,32]$.

In Fig. 6, we notice that the intensity of the E-O-R peak decreases as the annealing temperature increases. After annealing at $900^{\circ} \mathrm{C}$ for $1 \mathrm{hr}$. the E-O-R peak is reduced by more than a factor of two. Maher el. al [26] have studied the annealing of implantation induced defects and observed the coarsening of the E-O-R defects into resolvable a/c dislocation loops for self implanted Si to a dose of $10^{14}-10^{15} / \mathrm{cm}^{2}$ after rapid thermal annealing at $1200^{\circ} \mathrm{C}$ for 5 seconds. The coarsening of the E-O-R defects after high temperature annealing is also observed in Fig. 4.

The extent of the E-O-R defects in the samples with the different doses annealed at $900^{\circ} \mathrm{C}$ is shown in Fig. 7. Note that in the high dose sample not only the intensity of th E-O-R defects is much higher, the dechanneling rate in region of channel \#250-270 corresponding to the original amorphous layer region (also the $\mathrm{Si}_{1-\mathrm{x}} \mathrm{Ge}_{\mathrm{x}}$ region) is very high. This high dechanneling rate indicates a high density of defects present in this region consistent with the findings in the previous section from the values of the $\chi_{\min }(\mathrm{Ge})$, and is confirmed by the cross-sectional TEM micrograph shown in Fig.4.

$-1$

\section{SUMMARY}

$\cdots+$

We have studied the formation of buried epitaxial $\mathrm{Si}_{1-\mathrm{x}} \mathrm{Ge}_{\mathrm{x}}$ layers in (100) Si by the IBS

-technique. Strained defect-free $\mathrm{Si}_{1-\mathrm{x}} \mathrm{Ge}_{\mathrm{x}}$ layers with maximum $\mathrm{x}-0.04$ was synthesized by implanting $1 \times 10^{16} \mathrm{Ge}$ ions $/ \mathrm{cm}^{2}$ into Si at room temperature and annealed at $600^{\circ} \mathrm{c}$ for $10 \mathrm{~min}$. These strained layers become relaxed after annealing at temperatures higher than $800^{\circ} \mathrm{C}$. High dose implantation $\left(7 \times 10^{16} / \mathrm{cm}^{2}\right)$ and SPE results in the formation of a relaxed $\mathrm{Si}_{1-\mathrm{x}} \mathrm{Ge}_{\mathrm{x}}$ layer (maximum $x-0.13$ ) with high defect density. The implantation induced defects, namely threading dislocations and stacking faults in the layers and the E-O-R defects below the a/c interface can be reduced by annealing at temperanures higher than $900^{\circ} \mathrm{C}$. No redistribution of the Ge atoms is detected even after anr, aling at $900^{\circ} \mathrm{C}$ for $5 \mathrm{hrs}$.

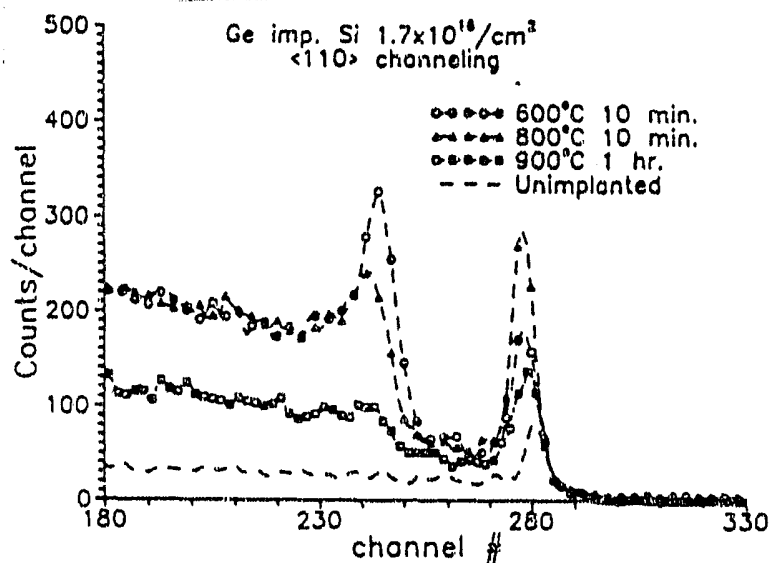

Fig. 6 A series of $<110>$ aligned RBS spectra from an unimplanted Si and medium dose samples annealed at various conditions.

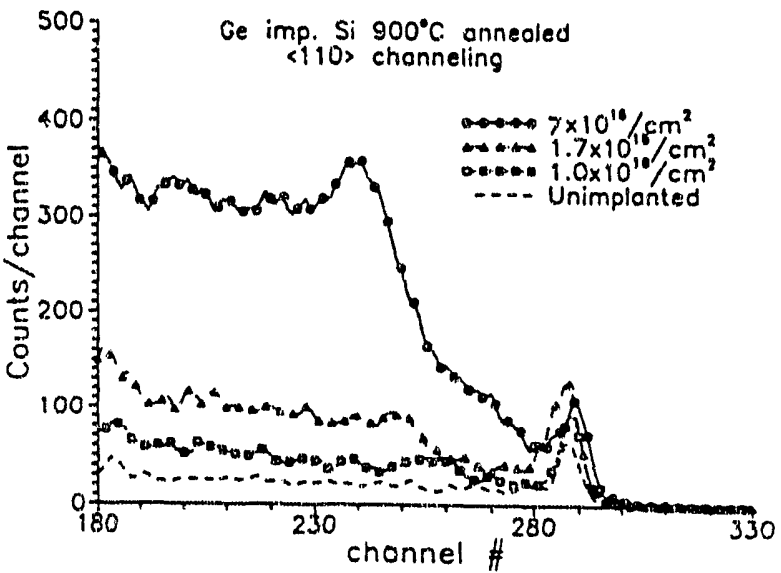

Fig. $7<110>$ aligned RBS spectra of the samples with different $\mathrm{Ge}$ doses annealed at $900^{\circ} \mathrm{C}$. 
This work was supported by the Director, Office of Energy Research, Office of Basic Energy Sciences, Materials Science Division of the U. S. Department of Energy under Contract No. DE-ACD3-76SF00098.

\section{REFERENCES}

1. G. Abstreiter, H. Brugger, T. Wolff, H. Jorke, and H. J. Herzog, Phys. Rev. Lett. 54, 2441 (1985).

2. S. S. Iyer, G. L. Patton, S. L. Delage, S. Tiwari, and J. M. C. Stork, Proc. Symp. on Silicon Molecular Beam Epitaxy, Hawaii, 1987, eds. J. C. Bean and L. J. Schowalter (The Electrochemical Soc. Inc.) p. 114.

3. J. C. Bean, T. T. Sheng, L. C. Feldman, A. T. Fiory, and R. T. Lynch, Appl. Phys. Lett. 44, 102 (1984).

4. C. A. King, J. L. Hoyt, C. M. Grant, J. F. Gibbons, M. P. Scott, and T. Turner, IEEE Electron. Dev. Lett. EDL-10, 52 (1989).

5. F. Meyer, M. Zafrany, M. Eisenberg, R. Beserman, C. Schwebel, and C. Pellet, J. Appl. Phys. 70, 4268, (1991).

6. J. W. Methews, Epitaxial Growth ed., J. W. Methews (Academic Press, 1974) p.5\%9.

7. R. Hull and J. C. Bean, Mat. Res. Soc. Symp. Proc. 148, 309 (1989).

8. D. J. Howard, D. C. Paine, and N. G. Stoffel, Mat. Res. Soc. Symp. Proc. 187, 279 (1991).

9. D. C. Paine, D. J. Howard, N. G. Stoffel, J. A. Horton, J. Mater. Res. 5, 1023 (1990).

10. M. Berti, G. Mazzi, L. Calcagnile, A. V. Drigo, P. G. Merli, and A. Migliori, J. Mater. Res. 6, 2120 (1991).

11. D. C. Paine, D. J. Howard, and N. G. Stoffel J. Electron. Mater. 20, 735 (1991).

12. A. White, K. T. Short, R. C. Dynes, J. P. Garno, and J. M. Gibson, Appl. Phys. Lett. 50, 95 (1987).

13. A. White, K. T. Short, R. C. Dynes, R. Hull, and S. M. Vandenberg, Nucl. Instrum. Meth. B39, 253 (1989).

14. S. Mantl, R. Jebasinski, and D. Hartman, Nucl. Instrum. Meth. B59/60, 666 (1991).

15. M. F. Wu, A. Vantomme, G. Langouche, H. Vanderstraeten, and Y. Bruynseraede, Nucl. Instrum. Meth. B54, 444 (1991).

16. R. S. Spraags, K. J. Reeson, R. M. Gwilliam, B. J. Sealy, A. DeVeirman, and J. vanLanduyt, Nucl. Instrum. Meth. B55, 836 (1991).

17. J. K. N. Lindner and E. H. teKaat, J. Mater. Res. 3, 1238 (1988).

18. J. K. N. Lindner, T. Klassen, and E. H. teKaat, Nucl. Instrum. Meth. B59/60, 655 (1991).

19. K. M. Yu, B. Katz, and I. G. Brown, Nucl. Instrum. Meth. B58, 27 (1991).

20. F. Namavar, F. H. Sanchez, J. I/ Budnick, A. H. Fasihudin, and H. C. Hayden, Mat. Res. Soc. Spring Meeting, 1987, Symp. C, Anaheim, CA.

21. T. L. Alford and J. C. Barbour, Mat. Res. Soc. Symp. Proc. 157, 137 (1990).

22. I. G. Brown, M. R. Dickinson, J. E. Galvin, X. Godechot, and R. A. MacGill, Nucl. Instrum. Meth. B55, 506 (1991).

23. I. G. Brown, B. Feinberg, and J. E. Galvin, J. Appl. Phys. 63, 4889 (1988).

24. G. L. Olson and J. A. Roth, Mater. Sci. Reports 3, 1 (1988).

25. D. C. Paine, N. D. Evans, and N. G. Stoffel, J. Appl. Phys. 70, 4278 (1991).

26. D. M. Maher, R. V. Knoell, M. B. Ellington, and D. C. Jacobson, Mat. Res. Soc. Symp. Proc. 52, 93 (1986).

27. R. Flagmeyer and M. Höricke, Nucl. Instrum. Meth. B30, 219 (1988).

28. Kin Man Yu and K. T. Chan, Appl. Phys. Lett. 56, 45 (1990).

29. B. J. Robinson, B. T. Chilton, P. Ferret, and D. A. Thompson, Mat. Res. Soc. Symp. Proc. 160, 353 (1989).

30. B. Holländer, S. Mantl, B. Stritzker, H. Jorke, and E. Kasper, J. Mater. Res. 4, 163 (1989).

31. J. Thornton, P. L. E. Hemment, and I. H. Wilson, Nucl. Instrum. Meth. B19/20, 307 (1987).

32. J. Thomton, K. C. Paus, R. P. Webb, I. H. Wilson, and G. R. Booker, J. Phys. D: Appl. Phys. 21, 334 (1988). 

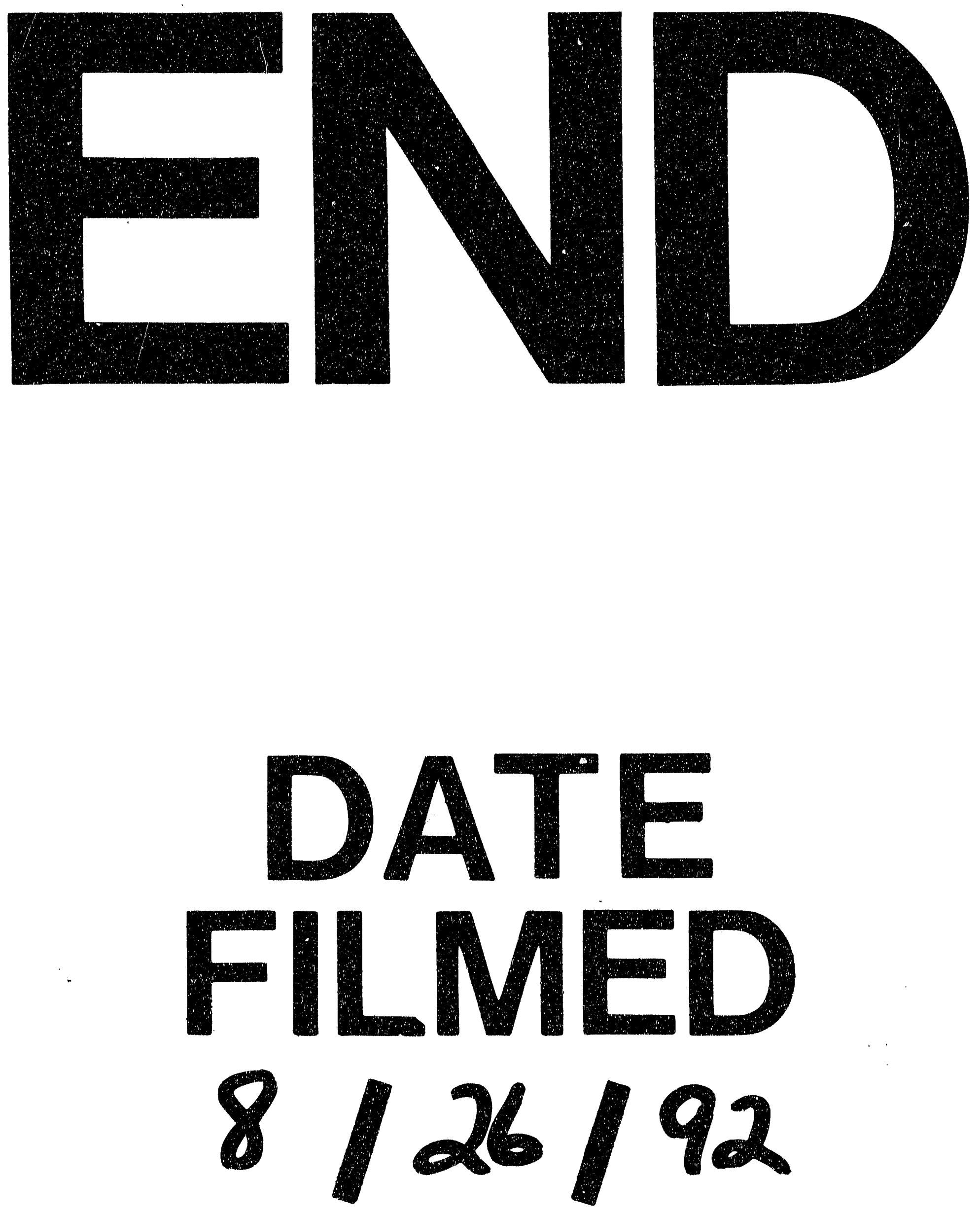
